\title{
EFFECT OF TEMPERATURE IN ELECTROCAPACITY IN-PROCESS CONTROL OF CABLE PRODUCTS
}

\author{
Nadezda Starikova*, Vitaly Redko, Ludmila Redko and Nikolay Ermoshin \\ Tomsk Polytechnic University, Institute of Non-Destructive Testing, 634050, Tomsk, Russia
}

\begin{abstract}
In this paper the analysis of temperature effect on the value of cable capacitance per unit length during its manufacture is provided. The physical model of cable product is developed. This model involves heat and electric components. The single-wire electric cable NV-3 insulated with plastic compound of PVC is chosen as a research object.
\end{abstract}

\section{Introduction}

In-process control is one of the most important stages of cable manufacture in factories. During the manufacture it is necessary to control such parameters as eccentricity [1], external diameter [2], length of cable product, dielectric strength of insulation and cable capacitance per unit length [3].

Cable capacitance per unit length is informative parameter for cable insulation quality control. The cable product (wire) can be represented as cylindrical capacitor. The first plate of it is core, the second plate is conductor or conducting medium on the insulation surface and the dielectric is wire insulation. According to the known formulae a capacity of cylindrical capacitor depends on geometrical dimensions and dielectric constant of the capacitor insulation material disposed between the plates. Thus, the core diameter, the diameter of the wire insulation, the length of controlled area of wire and the wire insulation material affect the value of cable capacitance.

\section{Research problem}

Nowadays the electrocapacity method is a widely used method of in-process control of cable insulation quality, which is based on measuring the value of capacitance per unit length of a manufactured wire [3-7]. The new method of in-process control of cable insulation quality was developed previously [8]. This method consists in measuring the capacitance per unit length of produced wire during spark test. The main point of both methods is an applying voltage between wire insulation surface and core, which is grounded. Then the capacitance per unit length is measured and the difference between measured and nominal values is the indicator of cable insulation quality.

* Corresponding author: starikovanadezda@mail.ru 
The nominal value of the capacitance per unit length is measured under normal conditions. In this case the ambient temperature is about $20^{\circ} \mathrm{C}$. But the technological regimes require significant heating a cable product and in-process control is carried out under insulation and wire temperatures which differs from normal. Consequently, the formula for the capacitance of a cylindrical capacitor can be presented as

$$
\begin{gathered}
C(T)=2 \pi \varepsilon_{0} \varepsilon_{r}(T) \frac{l}{\ln \left[R_{2}(T) / R_{1}(T)\right]} \\
R_{1}(T)=R_{1}+\Delta R_{1}=R_{1}+\alpha_{1} \cdot \Delta T \cdot R_{1} \\
R_{2}(T)=R_{2}+\Delta R_{2}=R_{2}+\alpha_{2} \cdot \Delta T \cdot R_{2}
\end{gathered}
$$

where $C$ is a capacitance, $\varepsilon_{r}$ is a relative permittivity, $l$ is a length of wire, $R_{l}$ is a core radius, $R_{2}$ is a external insulation radius, $\alpha_{1}$ is a coefficients of linear thermal expansion of a core material, $\alpha_{2}$ is a coefficients of linear thermal expansion of a insulation material.

Thus, it is necessary to assess the effect of temperature on the value of the capacitance per unit length. The single-wire electric cable NV-3 insulated with plastic compound of $\mathrm{PVC}$ is chosen as a research object.

\section{Assessment of the temperature operating range for cooling process during the manufacture}

The equipment for in-process control of capacitance per unit length can be placed in of extrusion line, after the cooling bath and in the stages of twinning and repackaging. The place of the control equipment depends on the realized method of in-process control.

During the extrusion of insulation with application of a screw barrel the stock material is melted in the melt zone of the extruder. Then the plastic compound is push out through the die on moving core. The heating mode of extruder is chosen based on the type of insulation material. The temperature of the wire insulated with plastic compound of PVC after the die is $160-180^{\circ} \mathrm{C}$ [9]. After extrusion stage a wire is passing through the cooling bath for solidifying of insulation material. There is not strict requirement for cooling process of wire insulated with a plastic compound of PVC because of small value of the coefficients of linear thermal expansion $\left(20 \cdot 10^{-5} 1 /{ }^{\circ} \mathrm{C}[10]\right)$ and low turn for void and crack formation in insulation $[9,11]$. The cooling process is provided by means of cold tap water which temperature is about $20^{\circ} \mathrm{C}$.

After the cooling stage the insulation temperature from inner to upper layer shall not exceed temperature of a softening of the insulation material. This condition is necessary for manufacture of quality cable product. The insufficient cooling leads to formation such defects as surface cut, changing of external insulation diameter and thickness, wire eccentricity.

Because of amorphous properties the softening temperature of plastic compound of PVC is the glass transition temperature or temperature of transition from glassy state into a molten or rubber-like state. The glass transition temperature of plastic compound of PVC is $70-80^{\circ} \mathrm{C}$ [12]. But for the safety of the cable factory staff a cable product is cooled till $40-50^{\circ} \mathrm{C}[9,10]$ in practice.

Hence, in the beginning of cooling stage the temperature of the wire insulated with plastic compound of $\mathrm{PVC}$ is $160-180^{\circ} \mathrm{C}$ and after this stage the temperature is $40-50^{\circ} \mathrm{C}$. 


\section{The physical model}

To analyze the temperature effect on the value of cable capacitance per unit length the complex physical model was developed by means of the finite element analysis software COMSOL Multiphysics [13]. This mode simulates changing of the temperature field distribution during the insulation material cooling and also considers the electric field which is needed for the capacitance per unit length measuring.

\subsection{The thermal model}

The heated wire cooling process in the cooling bath is described, in general, by two types heat exchange: heat conductivity and convection. Radiative heat loses are negligible in comparison with the listed thermal exchange types. Heat conductivity provides the heat exchange from the centre of the cooled product to its surface. The water, which contacts with the surface of the cable, induces the cooling of the insulation by the forced external convection.

The initial conditions of the model (in cylindrical coordinates) are:

$$
T(r, \varphi, t=0)=180^{\circ} \mathrm{C}
$$

Suppose that the cooling process can be described by the Newton's law of cooling [14]. The boundary conditions for the insulation surface are:

$$
\begin{gathered}
-n \cdot(-\lambda \nabla T)=\alpha \cdot\left(T_{w}-T\right) \\
\alpha=f\left(L, V_{w}, T_{w}\right),
\end{gathered}
$$

where $\lambda$ is the coefficient of thermal conductivity, $\alpha$ is the heat transfer coefficient, $L$ is the length of the cooling bath, $T_{w}$ is the water temperature of the cooling bath, $V_{w}$ is the linear velocity of the core insulating. Suppose that the linear velocity of the core insulating is $1 \mathrm{~m} / \mathrm{s}$.

\subsection{The electrical model}

To measure the capacitance the alternative voltage is applied to the insulation surface, the core is grounded (Figure 1). Then the capacitance is measured by means of different methods (resonant method, I-V method [3]).

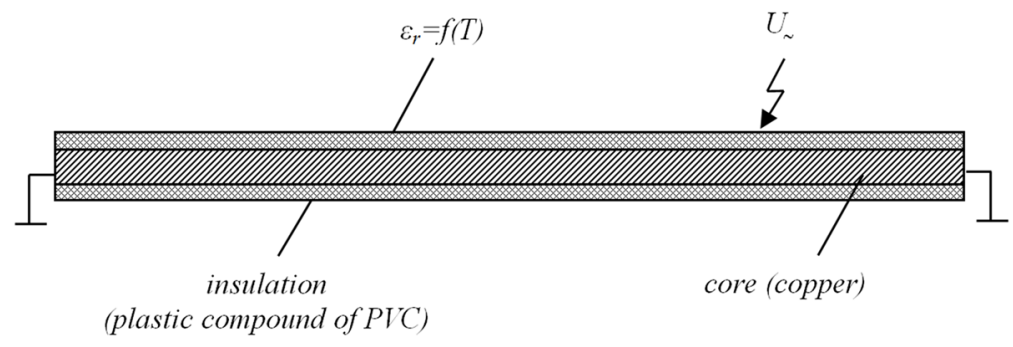

Figure 1. The electrical model of a wire.

The boundary conditions for the electrical model are:

$$
V\left(r=r_{c}, \phi, t\right)=0 \mathrm{~V}
$$




$$
V\left(r=r_{i n s}, \phi, t\right)=10 \cdot \sin (62800 \cdot t) \cdot V
$$

where $r_{c}$ is core radius, $r_{i n s}$ is insulation radius.

The dependence of the relative permittivity of the insulation material (plastic compound of PVC) from temperature is presented in the next graph (Figure 2) [12].

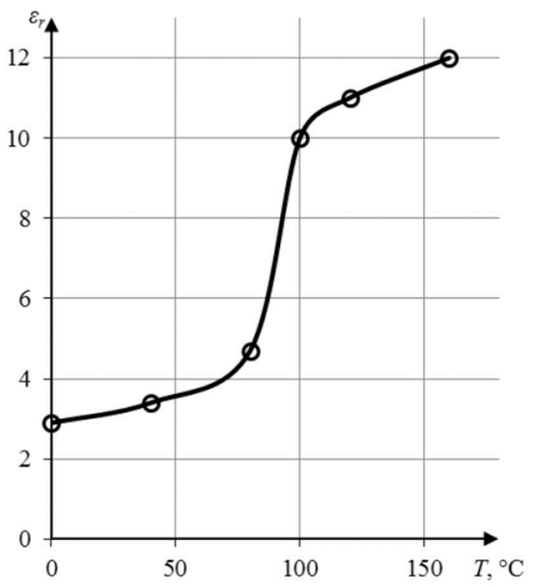

Figure 2. The dependence of the relative permittivity of the plastic compound of PVC from temperature.

It can be noted that the relative permittivity of the plastic compound of PVC is significantly affected by the temperature, which is considered in the model.

\section{Analysis of the of physical modelling results}

During the work the analysis of the effect of core and insulation thermal expansions on the capacitance per unit length is carried out. This effect is negligible because the coefficients of linear thermal expansions of core and insulation materials are small and leads to capacitance changing which is not exceed $1 \%$.

As a result of simulation the electric and heat fields distributions for insulation cross section are obtained. The Figures 3, 4 show the electric and heat fields distributions at the initial time moment after the wire to be immersed into water of the cooling bath.

According to the heat field distribution at the initial time moment (Figure 3) it can be noted that almost all thermal gradient is in near-surface layers. It is based on change of heat transfer mechanisms at the insulation surface. During following cooling process the thermal gradient is more uniform through the insulation.

The electric field distribution is nearly constant during the cooling process because the insulation thickness is small and the thermal gradient through the insulation is insignificant [15]. An exception is the electric field distribution for the glass transition temperature range of plastic compound of PVC. 


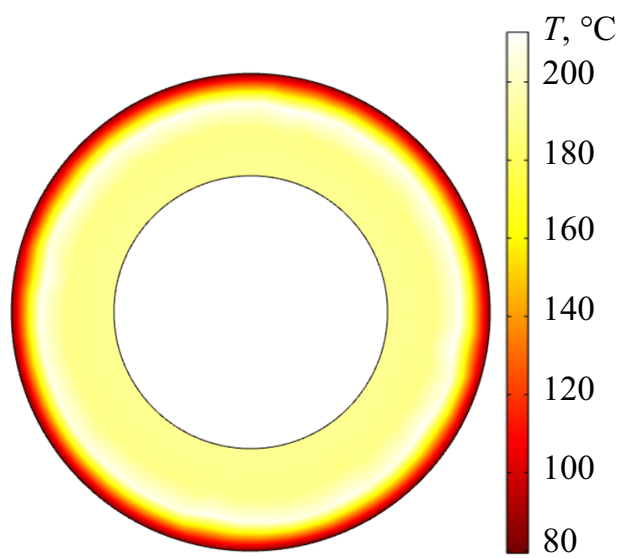

Figure 3. The heat field distribution for insulation cross section at the initial time moment.

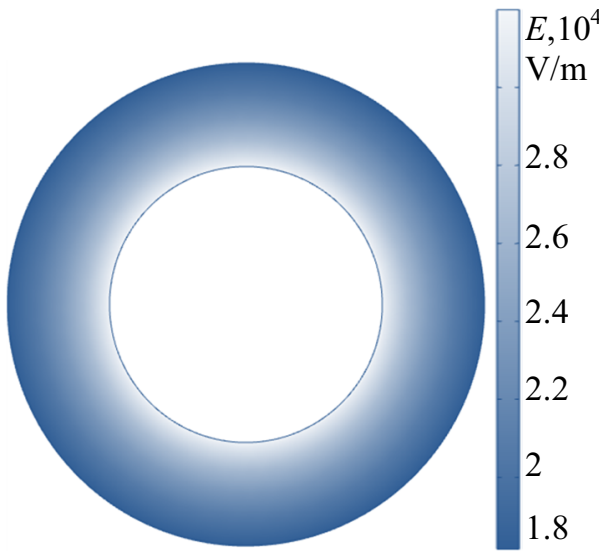

Figure 4. The electric field distribution for insulation cross section at the initial time moment.

In the next figure the obtained dependence $\delta(\tau)$ is shown (Figure 5), where $\delta$ is deviation of the capacitance per unit length from the nominal value, $\tau$ is cooling time, expressed in relative units in such way that the insulation material have transited into glassy state and the temperature of insulation surface becomes lower $40^{\circ} \mathrm{C}$ at the relative time $\tau=1$. The value of $\delta(\tau)$ is always positive because the value of the capacitance per unit length increases while heating.

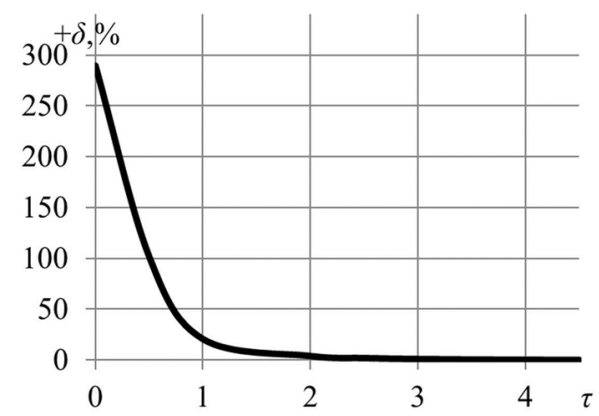

Figure 5. The dependence of the capacitance per unit length deviation from the cooling time.

According to this graph it can be noted that the deviation of the capacitance per unit length is $20 \%$ at the relative time $\tau=1$.

\section{Conclusion}

It is important to evaluate correctly the capacitance per unit length of the cable product for the reliable in-process control. For the correct evaluation of capacitance per unit length the location of the control device must be considered.

On the twinning and repackaging stages, when the temperature of the product is constant and equals to the ambient temperature, thermal effects are negligible for nominal value definition. For the measure of the capacitance per unit length in the cooing bath or after the cooling process it is necessary to consider the cooling regime of the insulation 
material and introduce the correction coefficients for the nominal value definition. Taking into account the thermal effects in the insulation material can lead to the measurement accuracy enhancement and hence improve the reliability of the cable product in-process quality control.

\section{References}

[1] A.E. Goldshtein, E.M. Fedorov, Rus. J. Nondestr. Test. 46, 424 (2010) doi: $10.1134 / \mathrm{S} 1061830910060069$

[2] E.M. Fedorov, I.D. Bortnikov, Tech. Phys. 60, 1689 (2015) doi: $10.1134 /$ S1063784215110110

[3] A.E. Goldshteyn, G.V. Vavilova, V.Y. Belyankov, Russ. J. Nondestr. Test. 51, 86 (2015) doi: 10.1134/S1061830915020047

[4] A.M. Pritulov, R.U. Usmanov, O.V. Gal'Tseva, A.A. Kondratyuk, V.V. Bezuglov, V.I. Serbin, Russ Phys Journal 50, 187 (2007) doi: 10.1007/s11182-007-0026-3

[5] O.V. Vasileva, Y.N. Isaev, A.A. Budko, A.I. Filkov, J. Phys.: Conf. Ser. 552, 012026 (2014) doi: 10.1088/1742-6596/552/1/012026

[6] A.A. Bespalko, A.P. Surzhikov, L.V. Yavorovich, P.I. Fedotov, Russ. J. Nondestr. Test. 48, 221 (2012) doi: 10.1134/S1061830912040043

[7] A.A. Bespalko, L.V. Yavorovich, P.I. Fedotov, Russ. J. Nondestr. Test. 47, 680 (2011) doi: 10.1134/S1061830911100068

[8] N.S. Starikova, V.V. Redko, G.V. Vavilova, J. Phys.: Conf. Ser. 671, 012056 (2016) doi: 10.1088/1742-6596/671/1/012056

[9] V.M. Leonov, I.B. Peshkov, I.B. Ryazanov, S.D. Holodnyj, Osnovy kabel'noj tekhniki (Akademiya, Moscow, 2006)

[10] I.D.Troickij, Proizvodstvo kabel'nyh izdelij (Vysshaya shkola, Moscow, 1988)

[11] V.A. Privezencev, Osnovy kabel'noj tekhniki (Energiya, Moscow, 1975)

[12] P.P. Nikotin, Materialy kabel'nogo proizvodstva (Gosehnergoizdat, Moscow, 1963)

[13] A.V. Abramova, E.V. Ivanova, P.A. Strizhak, MATEC Web of Conferences 23, 01001 (2015) doi: 10.1051/matecconf/20152301001

[14] T. Sebesi, P. Brehdshou, Konvektivnyj teploobmen (Mir, Moscow, 1987)

[15] V.N. Mitroshin, J. of Samara State Technical University : Ser. Phys. and Math. Sc. 38, (2005) 